\title{
Nesting material and number of females per cage: effects on mouse productivity in BALB/C, C57BL/6J, DBA/2 and NIH/S mice
}

\author{
Satu Eskola \& Eila Kaliste-Korhonen \\ National Laboratory Animal Center, University of Kuopio, Kuopio, Finland
}

\begin{abstract}
Summary
Two different materials-aspen wood-wool and paper towel-were compared as nesting material for three inbred mouse strains (BALB/C, C57BL/6J and DBA/2) housed in barrier conditions. In addition, the effect of varying the number of females per cage (one to three per cage) of these three strains and with NIH/S outbred mouse stock was studied. The number of litters, litter size and neonatal mortality were determined, as well as age, sex and weight of weanlings. The type of nesting material did not affect the characteristics monitored. In all strains, the number of weanlings per female was greatest in singly-housed females. In terms of the number of weanlings per cage, two females per cage gave the best result. In DBA/2 mice, neonatal mortality increased when several females were caged together.
\end{abstract}

Keywords Nesting material; productivity; stocking density; female mice

Nest building, using almost any material available, is typical rodent behaviour. Provision of nesting material is a method of enrichment and is considered to have more obvious welfare consequences for rodent species than other cage additions (e.g. toys) (Brain et al. 1993). Materials commonly used include straw, hay, paper or wood shavings. When testing the preference of mice for different types of nesting material, van de Weerd et al. (1996) found that male mice showed equal preference for wood and paper materials; their ability to manipulate the nesting material seemed to be important.

Reproductive success is known to be affected by breeding method. Mice are usually kept as monogamous pairs or harems; one male is kept in a cage with one or several females throughout the breeding period. The ratios of males to females can

Correspondence to: Satu Eskola, National Laboratory Animal Center, University of Kuopio, PO Box 1627, FIN-70211 Kuopio, Finland. Tel: +35817163 346, Fax: +35817163 353, E-mail: Satu.Eskola@uku.ff vary from $1: 1$ up to $1: 7$ (Festing 1987). Higher stocking ratios have been associated with decreased numbers of weanlings per female (Heine 1965). There are, however, differences in litter size, litter interval and neonatal mortality between different mouse strains (Festing 1968). The type of bedding material can also affect reproductive performance; provision of deodorized cellulose bedding decreased litter size, number of weanlings and diminished lactation, when compared with sawdust bedding (Iturrian \& Fink 1968, Cunliffe-Beamer \& Les 1987). Also the enzyme-inducing and cytotoxic properties of different contact beddings and nesting materials have been investigated (Kärenlampi \& Törrönen 1990, Potgieter et al. 1995, Pelkonen \& Hänninen 1997). The possible effects of nesting material on other production parameters have not been studied.

The aim of this study was to compare new nesting material (aspen wood-wool) with our standard material (paper towel) in mouse 
breeding. Furthermore, the effect of various breeding systems on productivity was compared between different strains.

\section{Materials and methods}

\section{Animals and environment}

Inbred $\mathrm{BALB} / \mathrm{c}(n=81$ females, 32 males $/ 32$ cages), C57BL $/ 6 \mathrm{~J}(n=41$ females, 20 males/ 20 cages) and DBA/2 ( $n=71$ females, 24 males/24 cages) mice (National Laboratory Animal Center, Kuopio, Finland) and outbred $\mathrm{NIH} / \mathrm{S}$ mice $(n=30$ females, 15 males $/ 15$ cages) (National Public Health Institute, Kuopio, Finland), were maintained in SPF barriers. The number of females caged with one male varied from one to three (Table 1). Mice were housed in stainless steel solid bottom cages $(42 \times 25 \times 15 \mathrm{~cm})$ with aspen bedding (chip size $4 \times 4 \times 1 \mathrm{~mm}$, Tapvei Oy, Kaavi, Finland). Cages were changed once a week. The room temperature was $22.5 \pm 1^{\circ} \mathrm{C}$ and relative humidity was $57 \pm 5 \%$. The artificial light/dark cycle was $12: 12$ with lights on at $07: 00 \mathrm{~h}$ and there was an average of 10-15 air changes per hour. Pelleted rat and mouse food (R36, Lactamin AB, Stockholm, Sweden) and tap water were available ad libitum. The tap water was filtered and UV-irradiated and cage equipment, bedding, food and nesting materials were autoclaved.

Table 1 The experimental breeding groups with two different nesting materials

\begin{tabular}{llll}
\hline & $\begin{array}{l}\text { Females } \\
\text { per cage }\end{array}$ & $\begin{array}{l}\text { Paper } \\
\text { towel }\end{array}$ & $\begin{array}{l}\text { Aspen } \\
\text { wood-wool }\end{array}$ \\
\hline $\begin{array}{lll}\text { Inbred } \\
\text { BALB/C }\end{array}$ & 1 & 4 cages & 2 cages \\
& 2 & 12 cage & 2 cages \\
& 3 & 3 cages & 11 cages \\
C57BL/6) & 1 & 5 cages & 2 cages \\
& 2 & 4 cages & 3 cages \\
& 3 & 5 cages & 7 cages \\
DBA/2 & 1 & 3 cages & 4 cages \\
& 2 & 7 cages & 8 cages \\
& 3 & & - \\
Outbred & & 5 cages & - \\
NIH/S & 1 & 5 cages & - \\
& 2 & 5 cages & - \\
& 3 & &
\end{tabular}

\section{Experimental procedure}

Inbred mice were offered aspen nesting material (Tapvei Oy, Kaavi, Finland) or one paper towel made of recycled pulp (Metsä Serla, Finland) for nesting (Table 1). The nesting material was in the form of woodwool made from aspen (Fig 1). A handful of aspen nesting material was placed into the cages; the amount was not weighed. Cages without nesting material were not used, because breeding female mice without possibilities to form nests is not recommended. In this study the cages with paper towels were considered as controls, since that is the standard breeding situation in our facility. $\mathrm{NIH} / \mathrm{S}$ mice were taken into the experiment later with the purpose of studying the effects of strain and female number in the cage on reproduction. For them, only paper towel was used for nesting. Productivity of inbred strains was monitored during six months from September 1995 till February 1996. Productivity of outbred NIH/S mice was determined during five months from March 1996 till July 1996.

The number of litters, newborns and weanlings as well as age, sex and weights of weanlings were recorded. Mortality of newborns was calculated by subtracting the number of weanlings from the number born and expressed as percentages per cage. Since animals used in this study were part of the normal production system, the number of cages and females varied slightly during the study. Bias was eliminated by matching pro-

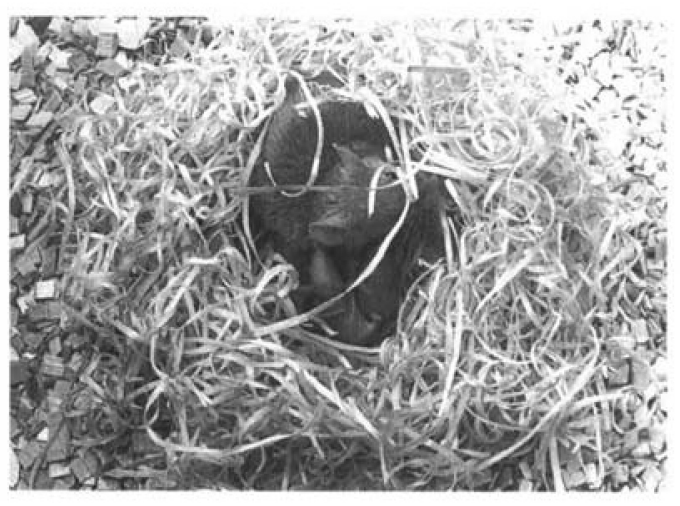

Fig 1 Female with neonates in nest made from aspen wood-wool 
ductivity indices with the number of months the animals in the cage were breeding (i.e. the productivity results are expressed per month).

The procedures and husbandry of animals used in this study were in accordance with the European Convention for the protection of vertebrate animals used for experimental and other scientific purposes (1990). The study was approved by the Ethical committee of Animal Experiments of the University of Kuopio.

\section{Statistical analysis}

Data were processed with the SPSS/PC+ V5.1 program (SPSS Europe B.V., Gorinchem, The Netherlands). Distribution of data was tested with the Kolmogorov-Smirnov test. The statistical tests used are indicated in the Results section. The independent factors studied were strain of mouse, type of nesting material and number of females per cage.

\section{Results}

According to our animal caretakers, the aspen nesting material seemed to be more durable and stayed cleaner than the paper towel. This was not however, quantified in any way. When several females shared a cage, they all delivered their pups into the same nest. Frequently, nests lost their structure during the week and fresh material had to be provided at cage changing. Those in good condition were not changed, with the purpose of avoiding unnecessary disturbance of pups and mothers, and animals seemed to be comfortable also in more than one-week-old nests.

As a main factor, there were no differences between these two nesting materials in any of the characteristics studied $(P>0.05$ MANOVA analysis or Mann-Whitney U-test, Table 2). Nor were the weight or age at weaning influenced by the quality of the nesting material $(P>0.05$ MANOVA analysis, Table 2) or number of females in cage (data not shown). The effect of nesting material on the productivity parameters of three inbred mouse strains was quite similar (interaction of nesting material and strain in MANOVA analysis, $P>0.6 \mid$. Outbred NIH/S mice had more litters/cage per month, larger litter size and more weanlings/cage per month than inbred strains $\mid P<0.05$ Scheffe test or multiple comparison between groups test, Siegel 1988, Table 2).

Litter size was not affected by the number of females per cage $(P>0.05$ one-way ANOVA analysis, Table 3). When comparing

Table 2 Productivity of four mouse strains with paper towel or aspen wood-wool for nesting

\begin{tabular}{|c|c|c|c|c|c|c|c|c|}
\hline & \multicolumn{2}{|l|}{$\mathrm{BALB} / \mathrm{C}$} & \multicolumn{2}{|l|}{ C57BL/6J } & \multicolumn{2}{|l|}{$\mathrm{DBA} / 2$} & \multicolumn{2}{|l|}{$\mathrm{NIH} / \mathrm{S}$} \\
\hline & $\begin{array}{l}\text { Aspen } \\
\langle n=15\rangle\end{array}$ & $\begin{array}{l}\text { Paper } \\
(n=17)\end{array}$ & $\begin{array}{l}\text { Aspen } \\
(n=8)\end{array}$ & $\begin{array}{l}\text { Paper } \\
(n=12)\end{array}$ & $\begin{array}{l}\text { Aspen } \\
(n=19)\end{array}$ & $\begin{array}{l}\text { Paper } \\
(n=15)\end{array}$ & $\begin{array}{l}\text { Paper } \\
(n=15)\end{array}$ & $\begin{array}{l}P \text { value } \\
\text { Strain/Nesting material }\end{array}$ \\
\hline $\begin{array}{l}\text { Litters/cage/ } \\
\text { month }\end{array}$ & $1.2 \pm 0.3$ & $1.0 \pm 0.5$ & $1.0 \pm 0.3$ & $0.9 \pm 0.3$ & $0.8 \pm 0.3$ & $0.9 \pm 0.3$ & $1.8 \pm 0.7^{\star}$ & $0.000 / \mathrm{NS}(\mathrm{K}-\mathrm{W}$ and $\mathrm{M}-\mathrm{W})$ \\
\hline Litter size $^{a}$ & $5.1 \pm 1.2$ & $4.5 \pm 1.4$ & $5.9 \pm 1.0$ & $5.5 \pm 1.7$ & $4.7 \pm 2.0$ & $4.5 \pm 1.3$ & $8.5 \pm 1.9^{*}$ & $0.002 /$ NS (MANOVA) \\
\hline $\begin{array}{l}\text { Weanlings/ } \\
\text { cage/month }\end{array}$ & $5.7 \pm 1.5$ & $4.4 \pm 2.0$ & $5.7 \pm 1.8$ & $4.9 \pm 2.0$ & $4.0 \pm 2.4$ & $4.0 \pm 2.0$ & $14.9 \pm 4.5^{*}$ & $0.000 /$ NS (MANOVA) \\
\hline $\begin{array}{l}\text { Neonatal } \\
\text { mortality } \%\end{array}$ & $10 \pm 8$ & $14 \pm 11$ & $10 \pm 10$ & $15 \pm 18$ & $19 \pm 30$ & $14 \pm 11$ & $14 \pm 13$ & $N S / N S(K-W$ and $M-W)$ \\
\hline $\begin{array}{l}\text { Age at } \\
\text { weaning (days) }\end{array}$ & $21 \pm 2$ & $21 \pm 3$ & $22 \pm 2$ & $22 \pm 2$ & $21 \pm 3$ & $21 \pm 3$ & $19 \pm 2$ & NS/NS (MANOVA) \\
\hline $\begin{array}{l}\text { Weight at } \\
\text { weaning (g) }\end{array}$ & $10 \pm 1$ & $10 \pm 1$ & $9 \pm 2$ & $10 \pm 2$ & $9 \pm 2$ & $9 \pm 2$ & $10 \pm 2$ & NS/NS (MANOVA) \\
\hline
\end{tabular}

\footnotetext{
"The NIH/S mice differed from the other strains, $P<0.05$ Scheffe test or multiple comparison between groups test (Siegel 1988)

Means \pm SDs are shown, $n=$ number of cages, $a=$ the number of females per cage was taken as a covariate and it had a significant effect $(P<0.03)$. NS $=P>0.05$. $\mathrm{K}-\mathrm{W}=$ Kruskall-Wallis test, $\mathrm{M}-\mathrm{W}=$ Mann-Whitney U-test
} 
Table 3 Productivity of four mouse strains at different number of females per cage

\begin{tabular}{|c|c|c|c|c|c|}
\hline Strain & Females in cage & Litters/cage/month & Mean litter size ${ }^{a}$ & Weanlings/cage/month ${ }^{a}$ & Neonatal mortality $\%$ \\
\hline \multirow[t]{3}{*}{$\mathrm{BALB} / \mathrm{C}$} & $1(n=6)$ & $0.7 \pm 0.1$ & $5.3 \pm 0.9$ & $3.8 \pm 1.0$ & $12 \pm 10$ \\
\hline & $2(n=3)$ & $1.4 \pm 0.6$ & $4.8 \pm 0.9$ & $4.9 \pm 2.0$ & $23 \pm 8$ \\
\hline & $3(n=23)$ & $1.2 \pm 0.4$ & $4.7 \pm 1.4$ & $5.3 \pm 2.0$ & $11 \pm 9$ \\
\hline \multirow[t]{3}{*}{ C57BL/6J } & $1(n=6)$ & $0.6 \pm 0.2^{2}$ & $5.7 \pm 1.3$ & $3.5 \pm 1.3^{2,3}$ & $5 \pm 8$ \\
\hline & $2(n=7)$ & $1.1 \pm 0.3$ & $5.2 \pm 1.8$ & $5.9 \pm 2.3$ & $22 \pm 21$ \\
\hline & $3(n=7)$ & $1.0 \pm 0.2$ & $6.2 \pm 1.2$ & $6.0 \pm 0.9$ & $11 \pm 9$ \\
\hline \multirow[t]{3}{*}{$\mathrm{DBA} / 2$} & $1(n=12)$ & $0.7 \pm 0.3$ & $5.0 \pm 1.4$ & $3.8 \pm 1.9$ & $5 \pm 7^{3}$ \\
\hline & $2(n=7)$ & $0.9 \pm 0.2$ & $5.2 \pm 1.2$ & $4.6 \pm 2.1$ & $13 \pm 13$ \\
\hline & $3(n=15)$ & $0.9 \pm 0.4$ & $4.0 \pm 1.9$ & $4.0 \pm 2.5$ & $28 \pm 31$ \\
\hline \multirow[t]{3}{*}{$\mathrm{NIH} / \mathrm{S}$} & $1(n=5)$ & $1.1 \pm 0.1^{3}$ & $10.1 \pm 2.2$ & $10.4 \pm 1.5^{2,3}$ & $7 \pm 13$ \\
\hline & $2(n=5)$ & $2.1 \pm 0.3$ & $7.8 \pm 1.4$ & $16.0 \pm 2.4$ & $18 \pm 14$ \\
\hline & $3(n=5)$ & $2.4 \pm 0.5$ & $7.7 \pm 1.2$ & $18.4 \pm 4.4$ & $17 \pm 12$ \\
\hline
\end{tabular}

When the Kruskall-Wallis test or one-way ANOVA test showed a significant effect of the number of females per cage, productivity indices were further analysed with a multiple comparison between groups test (Siegel 1988) or with a Scheffe test. Superscripts indicate groups from which marked groups differed $P<0.05$

Means \pm SDs are shown, $n=$ number of cages. a=nesting material was taken as a covariate but it had no significant effect $(P>0.05)$

the mean number of litters produced by paired females, the number seemed to be double that of monogamous pairs, except in DBA/ 2 mice. The difference was statistically significant, however, only in C57BL/6I mice $(P<0.05$ multiple comparison between groups test, Siegel 1988). Harems comprising three females did not, however, further increase the number of litters. In C57BL/6J and $\mathrm{NIH} / \mathrm{S}$ mice, the number of weanlings/cage per month was higher in cages with two or three females than in cages with one female $(P<0.05$ Scheffe test $)$. Only in $\mathrm{DBA} / 2$ mice was the neonatal mortality higher in cages with several females $\{P<0.05$ multiple comparison between groups test, Siegel 19881, even though it tended to be lowest in single-housed females in all strains (Table 3). The influence of the number of females per cage on productivity can also be seen in Fig 2. In all strains, productivity per female fell when the number of females per cage increased from 1 to $3\{P<0.05$ multiple comparison between groups test, Siegel 1988).

Table 4 shows the estimated number of cages needed each month to produce 100 weanlings, at different number of females. Two females per cage reduced the number of cages needed by four to 12 when compared with cages containing one female. Housing three females with each male does not

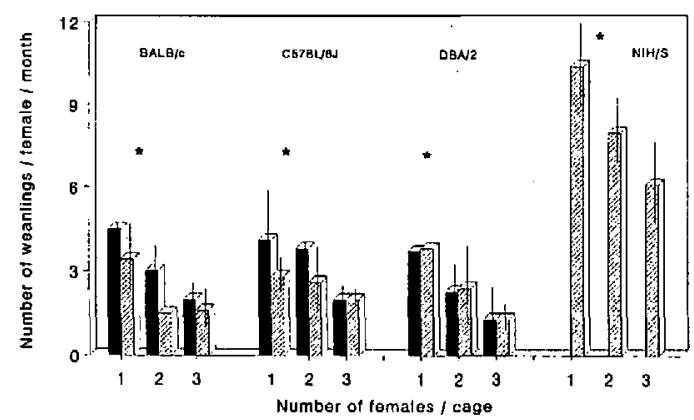

Fig 2 Number of weanlings/female in four mouse strains with aspen wood-wool or paper towel for nesting. ${ }^{*}$ Significant effects of female numbers in a cage when compared to cages with three females, $P<0.05$ (multiple comparison between groups according to Siegel 1988)

- Aspen 罗 Paper

greatly influence the number of cages needed, compared to cages containing two females.

Table 4 Calculated number of cages needed to produce 100 weanlings per month for the four different mouse strains

\begin{tabular}{llll}
\hline Strain & $\begin{array}{l}1 \text { female } \\
\text { per cage }\end{array}$ & $\begin{array}{l}2 \text { females } \\
\text { per cage }\end{array}$ & $\begin{array}{l}3 \text { females } \\
\text { per cage }\end{array}$ \\
\hline BALB/C & 26 & 20 & 19 \\
C57BL/6J & 29 & 17 & 17 \\
DBA/2 & 26 & 22 & 25 \\
NIH/S & 10 & 6 & 6 \\
\hline
\end{tabular}




\section{Discussion}

The two nesting materials tested were associated with similar productivity parameters. This indicates that they are equally suitable for breeding mice. Aspen nesting material, according to our caretakers, seemed to stay cleaner longer than paper towel, which might make it more comfortable for the animals. Moreover, the wood-wool is made of the same material as used for our bedding and so does not introduce any extra compounds into the cage environment. However, the chemical composition of paper may be superior to that of wood-wool since it has been shown that paper products in general have low cytotoxicity and enzyme inducing activity (Törrönen et al. 1989, Potgieter et al. 1995). Wood materials (softwoods and hardwoods) on the contrary, have been shown to be more cytotoxic than paper products (Potgieter et al. 1995, Pelkonen \& Hänninen 1997). Recycled paper, as the paper towel we used in this study, has been found to express stronger enzyme inducing properties than its bleached counterparts or non-bleached papers (Kärenlampi \& Törrönen 1990). Norris and Adams (1976) found a higher rat pup mortality when paper tissues $(53 \%)$ rather than wood-wool $(13 \%)$ were supplied as nesting material indicating the superiority of woodwool. They concluded that the decline was due to differences in nest-building and nest maintenance activities, but Potgieter et al. (1995) stated that it might also be a consequential cytotoxic effect. Our findings are based only on the breeding results; according to that, neither of the nesting materials was better than the other.

Productivity of females is not the only parameter to be considered when the production of laboratory animals is planned. For example, Festing (1987) claimed that a higher ratio of females to males would be more economical, even though productivity per female declines. The unit economic cost of breeding mice in cages containing one or three females is approximately the same. The number of cages needed, on the other hand, may be the critical factor in breeding facilities limited by the number of rooms or size. Table 4 shows that in order to produce 100 weanlings per month, the number of cages needed can be reduced from 10-29 cages to 6-22 cages, by housing two females in each cage, instead of one female. A third female in a cage does not reduce the number of cages needed. Hence, there is no reason to increase the number of females over two per cage. From an ethical point of view, the maintenance of unnecessary animals under laboratory conditions should be avoided.

The study confirmed previous findings that productivity per female is highest in cages with one female (Heine 1965). A significant increase in numbers of weanlings per cage with increasing numbers of females housed (from one to two and three) was seen only in C57BL/6J and NIH/S strains. The litter size remained statistically unaffected by the number of females per cage, although there seemed to be an indication of strain differences; C57BL/6J > BALB/c > DBA/2, which is in accordance with Festing (1979). On the other hand, the number of litters per cage did not increase in line with the number of females. Accordingly, the reason for the reduced productivity of females caged together was a reduction in the number of litters produced per female.

The declined number of litters might be due to alterations in the sexual cycle of females. It is known that group-housed female mice, when introduced to a male, will undergo a synchronized oestrus cycle, the socalled Whitten effect. Also pseudo-

pregnancies, which might be caused by social interactions (Marchlewska-Koj et al. 1994) may prolong the interval between oestrus periods (Harkness \& Wagner 1983). Social relationships and dominance hierarchies can have an influence on the reproductive performance by evoking termination of pregnancy if disturbance of homeostasis after fertilization occur (Marchlewska-Koj 1997) and inhibiting the reproduction of subordinant female by a dominant one (Parmigiani et al. 1989, vom Saal et al. 1995). On the other hand, in less aggressive strains two females were housed with a male and both females produced litters successfully (Parmigiani et al. 1989). The other explanation for the altered oestrus periods and declined number of litters may be the reduced space 
per female in the cage. In wild mice, the fertility of females is reduced when their locomotion activity is restricted (Andervont \& Dull 1962) and in crowded housing conditions the inhibition of the oestrus cycle has been observed (Marchlewska-Koj et al. 1994). However, this assumption is challenged by the fact that females nursed their pups together in the same nest. Finally, one more explanation for the reduced productivity might be an inhibitory effect of young on the oestrus cycle of females.

The neonatal mortality probably also had some effect (statistically significant only in $\mathrm{DBA} / 2$ mice) on the productivity. Virtually all pregnant females exhibit infanticide occasionally (McCarthy \& vom Saal 1985). Increased infanticide has been observed when both sibling and unfamiliar females have been housed together (Vom Saal et al. 1995). Since most of the mice in this study gave birth during night time, the mortality of newborns immediately after birth was undetected. However, the results indicate that the newborn mortality did occur in all four strains.

In conclusion, the nesting materials evaluated in this study resulted in a similar productivity by breeding mice. Moreover, the most effective breeding system, from the viewpoint of productivity per female is to cage one female with each male, although productivity per cage is highest in cages containing two females.

Acknowledgments We would like to thank the personnel in breeding units of National Laboratory Animal Center and National Public Health Institute for the help in practical work and Tapvei Oy as a supplier of aspen nesting material.

\section{References}

Andervont HB, Dunn TB (1962) Occurrence of tumours in wild house mice. Journal of National Cancer Institute 28, 1153-63

Brain PF, Büttner D, Costa P, et al. (1993) Rodents. In: The International Workshop on the Accommodation of Laboratory Animals in Accordance with Animal Welfare Requirements, Berlin 17-19 May (O'Donoghue PN, ed). Bonn, Germany: Bundesmi- nisterium für Ernährung, Landwirtschaft und Forsten, pp 1-14

Cunliffe-Beamer TL, Les EP (1987) The laboratory mouse. In: The UFAW Handbook on the Care and Management of Laboratory Animals, 6th edn. (Poole T, ed). Harlow: Longman Scientific \& Technical, pp 275-308

European Convention for the Protection of Vertebrate Animals used for Experimental and other Scientific Purposes (1990) European Convention given in Strasbourg 18March 1986, accepted in Finland 31 May 1990

Festing M (1968) Some aspects of reproductive performance in inbred mice. Laboratory Animals 2, 89-100

Festing M \{1979| Strain characteristics. In: Inbred Strains in Biomedical Research. London: Macmillan Press, pp 135-266

Festing $M$ (1987) Animal production and breeding methods. In: The UFAW Handbook on the Care and Management of Laboratory Animals, 6th edn. (Poole T, ed). Harlow: Longman Scientific \& Technical, pp 18-34

Harkness JE, Wagner JE (1983) The mouse. In: The Biology and Medicine of Rabbits and Rodents, 2nd edn. Philadelphia: Lea \& Febiger, pp 36-43

Heine W \{1965\} Problems of large scale production. Food and Cosmetics Toxicology 3, 223-8

Iturrian W, Fink G (1968) Comparison of bedding material: habitat preference of pregnant mice and reproductive performance. Laboratory Animal Care 18, 160-4

Kärenlampi S, Törrönen R (1990) Induction of cytochrome P4501A1 in mouse hepatoma cells as a short-term bioassay. Alternatives to Laboratory Animals (ATLA) 17, 158-62

Marchlewska-Koj A (1997) Sociogenic stress and rodent reproduction. Neuroscience and Biobehavioral Reviews 21, 699-703

Marchlewska-Koj A, Pochron E, Galewicz-Sojeca A, Galas J (1994) Suppression of estrus in female mice by the presence of conspecifics or by foot shock. Physiology and Behavior 55, 317-21

McCarthy MM, vom Saal FS (1985) The influence of reproductive state on infanticide by wild female house mice (Mus musculus). Physiology and Behavior 35, 843-9

Norris ML, Adams CE (1976) Incidence of pup mortality in the rat with particular reference to nesting material, maternal age and parity. Labora. tory Animals 10, 165-9

Parmigiani S, Brain PF, Palanza P (1989) Ethoexperimental analysis of different forms of intraspecific aggression in the house mouse. In: Ethoexperimental Approaches to the Study of Behavior (Blanchard R, Brain P, Blanchard D, Parmigiani S, eds). Dordrecht: Kluwer Academic, pp 418-31

Pelkonen KHO, Hänninen OOP (1997) Cytotoxicity and biotransformation inducing activity of rodent beddings. A global survey using the Hepa-1 assay. Toxicology 122, 73-80 
Potgieter FJ, Törrönen R, Wilke PI (1995) The in vitro enzyme-inducing and cytotoxic properties of South African laboratory animal contact bedding and nesting materials. Laboratory Animals 29, 163-71 Siegel S (1988) Nonparametric Statistics for the Behavioural Sciences, 2nd edn. New York: McGraw-Hill Book Company, p 213

Törrönen R, Pelkonen K, Kärenlampi S (1989) Enzyme-inducing and cytotoxic effects of woodbased materials used as bedding for laboratory animals. Comparison by a cell culture study. Life Sciences 45, 559-65
Van de Weerd HA, Baumans V, van Zutphen LFM (1996) Nesting material as enrichment in two mouse strains. Proceedings of Joint International Conference of ICLAS, Scand-LAS and FinLAS, Helsinki 1995. Scandinavian Journal of Laboratory Animal Science 23, 119-23

Vom Saal FS, Franks P, Boechler M, Palanza P, Parmigiani S (1995) Nest defense and survival of offspring in highly aggressive wild Canadian female house mice. Physiology and Behavior 58, $669-78$ 